\section{Integrated management of childhood illness}

\section{DESCRIPTION OF THE PROBLEM}

Every year in the world's developing countries, approximately 12 million children under the age of 5 die of illnesses that have been controlled or overcome in the developed countries. Acute respiratory infections (ARI), diarrheal diseases (DD), and malnutrition are among the five leading causes of death in children in most developing countries. In some areas, malaria is also a significant cause of disease and death. Measles, whose incidence and mortality had markedly decreased following vaccination campaigns in the countries, is re-emerging, even though progress is being made toward its elimination.

Five out of every 10 deaths of children under 5 in developing countries are from ARI and DD, which constitute the principal health problems of children. Malnutrition, malaria, and vaccinepreventable diseases cause an additional two out of 10 deaths. Thus, seven out of every 10 deaths of children under 5 years of age are attributable to this group of diseases and health problems. These deaths could be avoided by implementing measures for adequate prevention and early diagnosis and by providing proper treatment.

Taken together, this group of diseases is also responsible for $75 \%$ of the thousands of medical consultations for children under 5 who are taken by their parents to the health services each day. In addition, four of every five pediatric hospitalizations are attributable to these diseases-primarily pneumonia, diarrhea, and malnutrition. Many of these cases present severe complications due to the high prevalence of risk factors, such as low birthweight, the absence or short duration of breastfeeding, lack of vaccination (particularly against measles and whooping cough), household air contaminated by smoke (either from cigarettes or fossil fuels), and lack of basic sanitation (safe drinking water, sanitary disposal of excreta, and proper disposal of solid waste).

Acute diarrheal diseases, acute respiratory infections, malaria, measles, and malnutrition are the main reasons for the use-often improper-of diagnostic and treatment technologies by health personnel. The unnecessary use of antibiotics and the prescription of inappropriate drugs (cough and cold syrups, antidiarrheal preparations), the unnec- 
essary hospitalization of diarrhea cases, and the wasteful use of clinical diagnostic laboratories or radiology facilities are the primary examples of poor-quality treatment for prevalent childhood illnesses. In all cases, the unnecessary use of diagnostic and treatment technologies increases the cost of care without improving treatment of the disease.

The burden that treating these diseases and health problems imposes on health personnel and the health services also has an important impact on the quality of the care provided. The saturation of the health services with consultations often leads to poor evaluation and treatment of children. Overload of the services also limits the time that health personnel have to talk with mothers, resulting in missed opportunities for the early detection and proper treatment of other, co-existing problems, for the use of preventive measures such as vaccination, and for education about the care of children in the home and the prevention of risk factors.

\section{GENERAL POLICIES, OBJECTIVES, AND STRATEGIES FOR THEIR FULFILLMENT}

In recent years the need to step up control efforts in order to change the situation described above has led the World Health Organization (WHO) and the United Nations Children's Fund (UNICEF) to join forces to develop the strategy for Integrated Management of Childhood Illness (IMCI). The IMCI strategy is a useful tool for responding to the most frequent problems that affect children's health and for improving the care of children in the home. It includes the prevention of illness through vaccination in order to reduce the prevalence of risk factors that may cause and aggravate disease.

Within the framework of the commitments adopted by WHO and UNICEF at the global level to support the countries in the achievement of the goal of improving the health of children, the Pan American Health Organization, Regional Office of WHO for the Americas, and UNICEF-The American and Caribbean Regional Office (TACRO) have agreed on the objectives, strategies, and lines of action presented below to orient their work toward a better future for children in the Region of the Americas.

Implementation of the IMCI strategy will represent an important contribution to the following general policies:

- Strengthening the concept of integrated child health care in the health services by shifting the focus from the treatment of illness to the comprehensive care of the child's health, thus pro- viding opportunities for detecting the main problems that affect child health.

- Strengthening the planning and problem-solving capability of the first level of care by giving health workers the tools they need to properly manage the child health problems that are the most frequent causes of medical consultations.

- Achieving greater equity of access to adequate health care for children by making appropriate diagnostic and treatment technologies available to the population for the most frequent health problems.

- Strengthening community participation in the care and protection of child health through health education and mass communication that will improve the knowledge, attitudes, and practices of parents regarding the care of their children in the home during the first years of life.

Implementation of the strategy will contribute to the achievement of the following specific objectives:

- Reduction of mortality from diseases prevalent in children under 5 years of age, specifically, deaths from malnutrition, DD, ARI, malaria, and measles.

- Reduction of the occurrence and severity of cases of DD, ARI, and measles.

- Improvement of the quality of care for children at health facilities by diminishing the inappropriate and excessive use of diagnostic and treatment technologies.

The IMCI strategy for integrated management of childhood illness includes the following components:

- Evaluation of children and identification of warning signs.

- Evaluation of children with difficulty breathing and identification of signs of pneumonia.

- Evaluation of children with diarrhea and identification of signs of dehydration.

- Evaluation of fever and identification of signs of pneumonia, malaria, or measles.

- Evaluation of ear problems.

- Identification of signs of malnutrition and anemia.

- Evaluation of and advice on breast-feeding and other feeding practices.

- Evaluation of the immunization status of the child.

- Treatment of the diseases and health problems that have been detected, including intestinal parasites and skin diseases, in accordance with their prevalence and the local epidemiologic profile. 
- Education of children's caregivers on how to care for children in the home while they are sick and after recovery and what warning signs of serious illness to watch for in order to permit timely consultation.

\section{IMPLEMENTATION OF THE STRATEGY FOR INTEGRATED MANAGEMENT OF CHILDHOOD ILLNESS}

Implementation of this strategy at the country level to permit universal access to adequate child health care-which must include health promotion and disease prevention in the routine care provided in the health services and the community-is the main challenge facing the countries in the coming years in their efforts to meet the goals for the year 2000 established at the World Summit for Children.

$\mathrm{PAHO} / \mathrm{WHO}$ and UNICEF-TACRO have agreed to promote implementation of the IMCI strategy in the developing countries of the Region of the Americas. Specific lines of action will support a set of sequential activities that will be coordinated with the countries to achieve a rapid increase in the population's access to and use of the strategy's benefits.

$\mathrm{PAHO} / \mathrm{WHO}$ and UNICEF-TACRO have also called on all field offices, focal points, and advisory and technical officers, as well as the WHO Collaborating Centers and specialized centers, to support these proposed lines of action in order to reinforce efforts and optimize the use of existing resources.

On World Health Day 1997 (7 April), representatives of PAHO and the United States Agency for International Development (USAID) signed a letter of intent for a grant to PAHO for up to US\$ 2.8 million. These funds will be used to support implementation of the IMCI strategy in the countries of Latin America.

\section{Lines of action}

(1) Analysis of the epidemiologic situation, as well as efforts to control the principal health problems of children in each country. Available information on the magnitude and trends of the principal child health problems in the country as a whole and in its individual regions will be reviewed in order to identify the areas where the strategy will potentially have the highest impact. In order to prioritize activities according to degree of risk encountered, this analysis will focus especially on the situation in places where access to children's health care is difficult, i.e., areas that are geographically or cultur- ally isolated, areas with few health professionals, or areas where it is difficult to refer cases to health services at a higher level of complexity.

(2) Analysis of the strategy for integrated management of childhood illness and organization of its implementation in the country. This line of action includes identification of the existing structures that are participating in specific control activities and analysis of how they will participate in the implementation of the integrated strategy, as well as the establishment of coordination mechanisms at the Ministry of Health and among the various government entities and the extragovernmental sector-that is, NGOs and private health care services. It also entails presenting the foundations of the IMCI strategy and its characteristics to national officials so that they will be aware of the benefits of its implementation.

Technical teams at the national, regional, and local levels will analyze the need to incorporate specific health problems or exclude others (malaria, for example), based on the local epidemiologic situation. In this context the technical content of the IMCI strategy will be adapted at the national and local levels with a view to providing content that is appropriate to the epidemiologic situation, clinical diagnostic and treatment practices, and cultural aspects related to the implementation of disease prevention and health promotion measures in the population.

(3) Preparation of operational plans to implement the strategy for integrated management of childhood illness. Such preparation includes a detailed list of the programmed activities as well as the methodologies to be used to monitor, evaluate, and verify the progress made in comparison with the expected results.

(4) Training of health personnel in implementation of the strategy for integrated management of childhood illness. The staff responsible for the treatment of children in the local health services and other outpatient facilities, as well as those responsible for the planning of activities at the national, regional, and local levels, must be provided with appropriate training. Elements of the training given to health personnel responsible for treatment will include the criteria for evaluating, classifying, and treating prevalent illnesses in children. These staff should also receive training in how to properly educate and communicate with mothers of children under 5 to improve their knowledge of how to care for their children at home. This training will include a strong practice component to enable the staff to develop the necessary skills. 
Since the training will demand a significant investment of effort and resources over a relatively extended period, all existing resources will be used, especially the Training Units that already provide instruction in ARI and DD management and the professional educational institutions (medical and nursing schools). Involvement of the latter can guarantee the gradual incorporation of this component into undergraduate training.

There should also be intensive training for community health workers (health promoters, volunteers, etc.), utilizing all the available infrastructure, such as community oral rehydration units and the experience of NGOs in this field.

(5) Support for development of the logistics to furnish the supplies for implementing the strategy. These supplies include not only the drugs for treating children but the materials needed to train health personnel and educate those responsible for providing proper care to children in the home, as well as all other materials required to implement the strategy.

(6) Supervision of health personnel in the implementation of the strategy. Support to these staff for implementing the strategy in the workplace must be ensured. This component will therefore complement the training they receive and will play a strategic role in guaranteeing effective application of the IMCI strategy.

(7) Mass communication and health education for the population with regard to the strategy. The methodologies that are most appropriate for the local population will be utilized, involving not only the mass media but interpersonal communication between children's caregivers and health service personnel.

Since the kind of communication used will depend on the nature of the target population, a special effort will be made to gather information on the current knowledge, attitudes, and practices of the general population or specific sociocultural groups.

(8) Monitoring and evaluation of activities and results. This line of action will provide follow-up to the implementation process and monitoring of any partial results and will make it possible to predict the evolution of the problem and the expected impact of the intervention. It will include analysis of the coordination mechanisms that should be established, both inside and outside the Ministry of Health, for the acquisition, processing, analysis, and dissemination of the information on the monitoring process, together with an analysis of the need to conduct special surveys, research, and operational studies.

\section{SINOPSIS}

Millones de defunciones en niños menores de 5 años se podrían prevenir en países en desarrollo si se aplicaran las medidas de control y los tratamientos eficaces que se usan normalmente en países desarrollados. Conscientes de la necesidad de hacer frente a las principales causas de enfermedad y muerte en la infancia (infecciones respiratorias agudas, enfermedades diarreicas, desnutrición, malaria y enfermedades prevenibles por medio de la vacunación) mediante una iniciativa global, la OMS y el UNICEF han desarrollado una estrategia conocida por Atención Integrada de las Enfermedades Prevalentes de la Infancia (Integrated Management of Childhood Illness, IMCI). Sus oficinas regionales para las Américas, que son la OPS y el UNICEFTACRO, han aceptado los objetivos y actividades descritos en el presente informe a fin de reorientar su labor y dirigirla hacia el mejoramiento del estado de salud infantil en este hemisferio. 